\title{
Romanian National Guidelines and Practical Recommendations on Liver Elastography
}

\author{
Ioan Sporea ${ }^{1}$, Simona Bota ${ }^{1}$, Adrian Săftoiu ${ }^{2}$, Roxana Șirli' ${ }^{1}$, Oana Grădinaru-Tașcău${ }^{1}$, \\ Alina Popescu ${ }^{1}$, Monica Lupşor Platon ${ }^{3}$, Carmen Fierbințeanu-Braticevici ${ }^{4}$, \\ Dan Ionuț Gheonea ${ }^{2}$, Larisa Săndulescu ${ }^{2}$, Radu Badea ${ }^{3}$ \\ Under the auspices of Romanian Society of Ultrasound in Medicine and Biology (SRUMB)
}

\begin{abstract}
${ }^{1}$ Department of Gastroenterology and Hepatology, "Victor Babeș" University of Medicine and Pharmacy Timișoara, ${ }^{2}$ Department of Gastroenterology, Research Center of Gastroenterology and Hepatology, University of Medicine and Pharmacy Craiova, ${ }^{3}$ Department of Medical Imaging, Regional Institute of Gastroenterology and Hepatology, "Iuliu Hatieganu" University of Medicine and Pharmacy, Cluj Napoca, ${ }^{4}$ Department of Gastroenterology "Carol Davila" University of Medicine and Pharmacy Bucharest, University Hospital Bucharest, Romania
\end{abstract}

\begin{abstract}
The use of liver elastography has substantially developed in the past few years; the introduction of novel elastographic methods (Transient Elastography, point Shear Wave Elastography, Real Time Shear Wave Elastography, Strain Elastography) has changed the perspective in the evaluation of liver disease. The ongoing research in this area is mainly focused on diffuse liver diseases and for predicting liver cirrhosis complication. This guideline created under the auspice of Romanian Society of Ultrasound in Medicine and Biology is intended to accustomize the clinician with the current practical use of liver elastography and has been issued to help in maximizing the clinical benefit for the patients with chronic liver diseases.

Keywords: transient elastography, shear wave elastography, strain elastography
\end{abstract}

\section{Introduction}

Chronic liver diseases are frequent in the modern world. This situation is generated by chronic infection with hepatitis viruses (such as B or C), that still affect a large number of people (at least in some areas of the globe), by chronic alcohol abuse and by the diseases of the modern world: obesity, diabetes and hypertriglyceridemia (generating non-alcoholic fatty liver disease NAFLD). In these conditions, the evaluation of patients with chronic liver disease must be as simple as possible, not very expensive and in the same time repetitive.

Received 24.03.2014 Accepted 02.04.2014

Med Ultrason

2014, Vol. 16, No 2, 123-138

Corresponding author: Prof. Ioan Sporea, MD, PhD

13, Snagov Street, 300482 Timisoara, Romania

Phone: +40 256 309455, Fax: + 40256488003

E-mail: isporea@umft.ro
In the last decade we observed, especially in Europe, a decrease in the number of liver biopsies (LB), in favor of non-invasive modalities of evaluation (biological tests or elastographic evaluation), in patients with chronic liver disease. Among these, ultrasound (US) based elastographic methods showed an important development in the last ten years.

Considering these facts and having in mind that knowledge in this field is progressing very fast, we decided to issue these National Guidelines and Recommendations on liver elastography. Why Romanian Guidelines? Because in Romania, many FibroScan machines are available (at least 20-25), because in many centers "point" shear waves elastography is used in daily practice and because recently, real time shear waves (SWE) elastography became available. On the other hand, many Romanian good quality papers were published in important medical journals, so that the Romanian experience 
in US based elastography is extensive. We would like, in the same time, to formulate "practical recommendations" for people that will start using these methods.

\section{Physical principles of elastography and main ul- trasound based elastographic methods}

Classification of US based elastographic techniques

The available US based elastographic techniques are classified as follows, according to the European Federation of Societies for Ultrasound in Medicine and Biology (EFSUMB) Guidelines [1]:

1) Shear Wave Elastography (SWE) (quantitative elastography), which include:

a) Transient Elastography (TE) - the only method non-integrated into a standard ultrasound system

b) Point SWE:

- Acoustic Radiation Force Impulse Elastography (ARFI)

- ElastPQ technique

c) Real Time SWE:

- Two-dimensional SWE (2D-SWE)

- Three-dimensional SWE (3D-SWE)

2) Strain Elastography (quasi-static elastography, qualitative elastography): Real Time-Elastography (RT-E)

All available US elastographic methods need to measure tissue displacement. In strain elastography, it is mechanically induced (either by external manual compression or internally, by the heart beating). In SWE, the applied force is induced by the US probe (except TE, for which the force is also applied mechanically, but using an external transducer) [1].

\section{a) Transient Elastography}

This technique is integrated into a FibroScan ${ }^{\circledR}$ device (EchoSens, Paris, France), which incorporates a $3.5 \mathrm{MHz}$ US transducer (standard M-probe) mounted on the axis of a vibrator. The vibrator generates a completely painless vibration (with $50 \mathrm{~Hz}$ frequency and $2 \mathrm{~mm}$ amplitude), which induces an elastic shear wave propagating through the skin and the subcutaneous tissue to the liver, the shear wave being tracked using the coaxial ultrasound transducer. This wave's velocity is directly related to the tissue stiffness, which is calculated by the device and expressed in kilopascals $(\mathrm{kPa})[1,2]$. Beside the standard M-probe, an S-probe $(5 \mathrm{MHz})$ for pediatric use and an XL-probe $(2.5 \mathrm{MHz})$ for overweight and obese patients are available. The first version of the device displayed the median LS value, the IQR (Interquartile Range) interval, i.e the difference between the $75^{\text {th }}$ and $25^{\text {th }}$ percentile, essentially the range of the middle $50 \%$ of data and the SR (success rate), i.e the ratio of the number of successful

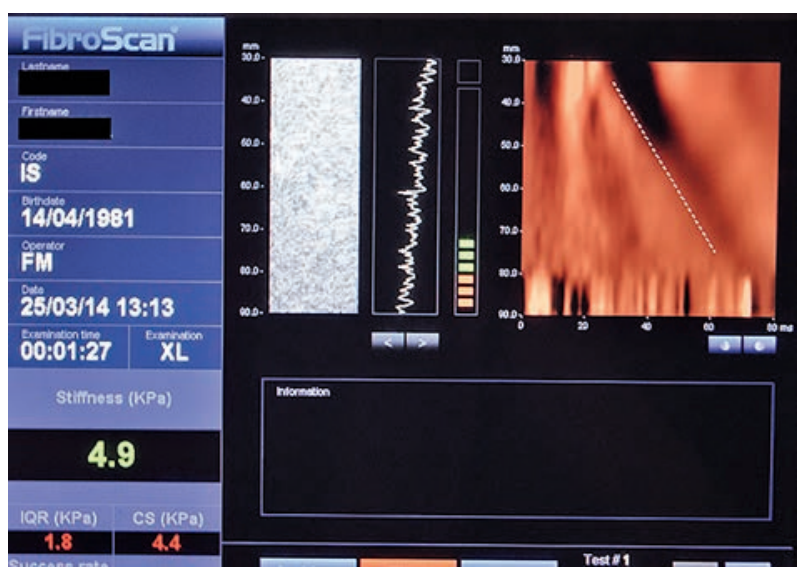

Fig 1. Transient Elastography

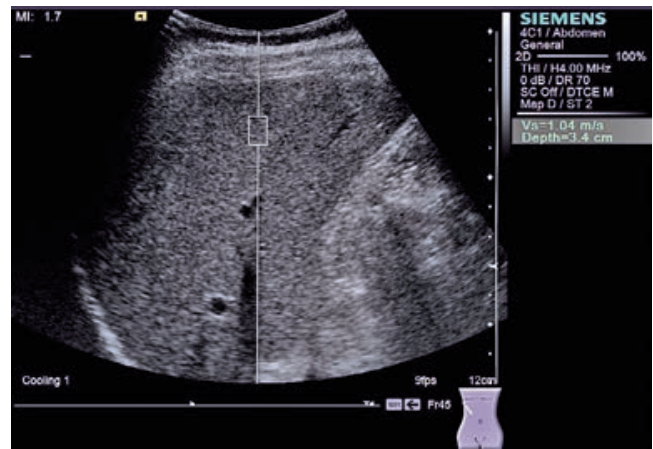

Fig 2. Acoustic Radiation Force Impulse Elastography

acquisitions over the total number of acquisitions (fig 1). The new version also quantifies liver steatosis, using the Controlled Attenuation Parameter (CAP).

b) Acoustic Radiation Force Impulse (ARFI) Elastography

ARFI is performed with a Siemens Acuson S2000 Virtual Touch ${ }^{\mathrm{TM}}$ US system (Siemens AG, Erlangen, Germany). The principle of ARFI elastography is that shearing of the examined tissue, induces a strain into the tissues. An acoustic "push" pulse is automatically produced by the US probe and directed to the side of a region of interest (ROI), which is where the shear wave speed is measured. This ROI has a predefined size, provided by the system ( $10 \mathrm{~mm}$ long and $5 \mathrm{~mm}$ wide). The acoustic "push" pulse generates shear-waves which propagate into the tissue, perpendicular to the "push" axis. Detection waves are also generated by the transducer, in order to measure the propagation speed of these shear-waves, which increases with fibrosis severity $[1,3]$. The shearwaves' speed, measured in meters/second $(\mathrm{m} / \mathrm{s})$, as well as the measurement depth are displayed by the system (fig 2). 


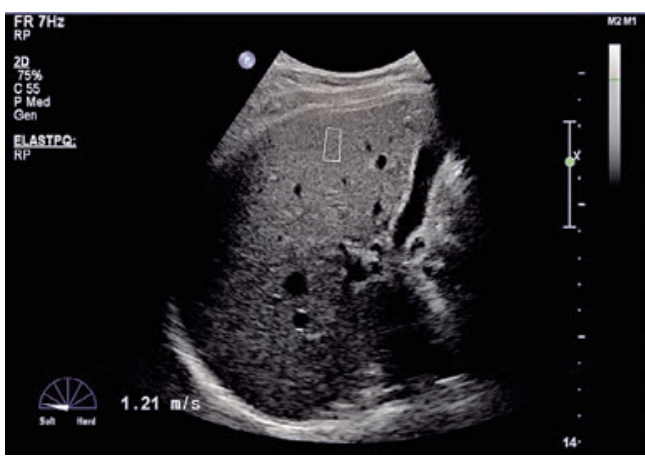

Fig 3. Elast $P Q$

\section{c) ElastPQ technique}

ElastPQ technique is integrated into a Philips ultrasound system (iU22, Philips Medical Systems, Bothell, WA, USA). Currently, little information is available regarding the physical principles of ElastPQ technique. According to the data provided by the manufacturer in the application for approval, submitted to the US Food and Drug Administration (FDA), ElastPQ system is relatively similar to 2D-SWE, even if this method is classified as a point SWE method. The ElastPQ system generates an electronic voltage pulse, which is transmitted to the transducer. In the transducer, a piezo electric array converts the electronic pulse into an ultrasonic pressure wave. When coupled to the body, the pressure wave transmits through body tissues. The Doppler functions of the system process the Doppler shift frequencies from the echoes of moving targets, such as blood, to detect and graphically display the Doppler shift of these tissues as flow. The Doppler mode creates waves in soft tissues and estimates tissue stiffness by determining the speed at which these shear waves travel through the ROI. Similar with ARFI elastography, ROI has a predefined size, provided by the system (15 $\mathrm{mm}$ long and $5 \mathrm{~mm}$ wide). The shear wave speed is displayed on the screen (fig 3). The operator can choose to display the results in $\mathrm{m} / \mathrm{s}$ or in $\mathrm{kPa}$.

\section{d) $2 D-S W E$}

This technique is integrated into an Aixplorer ${ }^{\mathrm{TM}}$ US system (SuperSonic Imagine S.A., Aix-en-Provence, France). The principle of $2 \mathrm{D}-\mathrm{SWE}$ is the combination of a radiation force induced into the tissues by focused ultrasonic beams and a very high frame rate ultrasound imaging sequence, able to capture the propagation of resulting shear waves in real time. The US system captures the generated shear waves. To capture them in sufficient detail, frame rates of a few thousands of images per second are needed. This ultrafast imaging mode acquires raw radiofrequency data at a very high frame rate, up to 5000 frames/s. The shear wave speed is then estimated

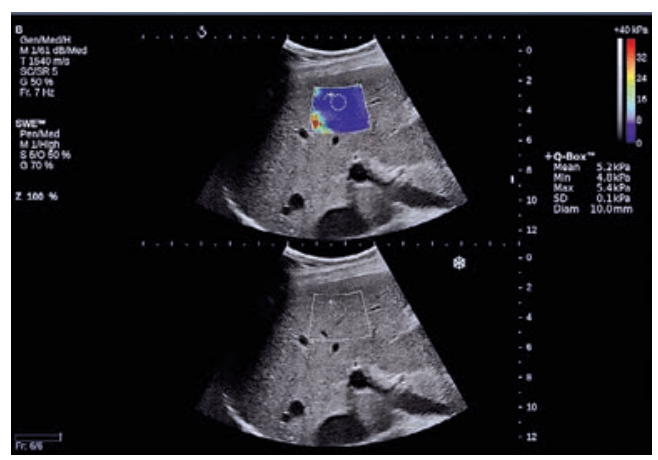

Fig 4. Two-dimensional Shear Wave Elastography

by a Doppler like acquisition over a ROI. The shear wave speed is used to calculate the tissue stiffness. Elasticity is displayed using a color coded image superimposed on a B-mode image: in red - stiffer tissues and in blue - softer tissues $[1,4,5]$. In the same time, a quantitative estimation of LS is performed, the mean LS value in the region of interest (whose size can be modified by the operator), as well as the standard deviation of the measured elasticity are displayed on the screen, expressed in $\mathrm{kPa}$, or, if the operator chooses, in m/s (fig 4).

\section{e) Strain Elastography}

This type of elastography was firstly developed by Hitachi, but today is available in almost all US systems. The principle of this technique is that an elastic medium is compressed with a constant, axial oriented pressure, producing deformations into the tissue. If one or more tissue constituent elements have different stiffness than the others, their deformation will be different. Longitudinal deformation is estimated by analyzing the ultrasonic signals obtained with conventional equipment in the following sequence: the region of interest is scanned and the set of appropriate radio-frequency echoes is digitized and stored; a tissue compression force is applied to produce small linear elastic deformation into the tissue and the region of interest is scanned once again and a new set of echo signals is acquired. Because the compressive stress amplitude is small, deformation and differences in propagation times are reduced. This technique is defined also as "quasi-static" elastography and it is a qualitative technique $[1,6]$. Initially, hand compression was used for tissue deformation, but in the newly developed systems, heart beatings are used to stress the tissue. Elasticity is displayed using a color coded image superimposed on a B-mode image: in red - softer tissues and in blue - stiffer tissues (fig 5). The new Hitachi system (HI VISION Preirus and Ascendus) also displays a histogram and eleven parameters which are used to calculate the liver stiffness (fig 6). 


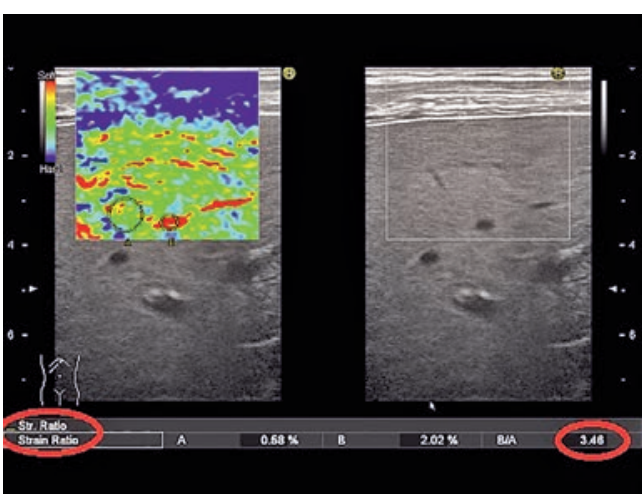

Fig 5. Strain Elastography - first version

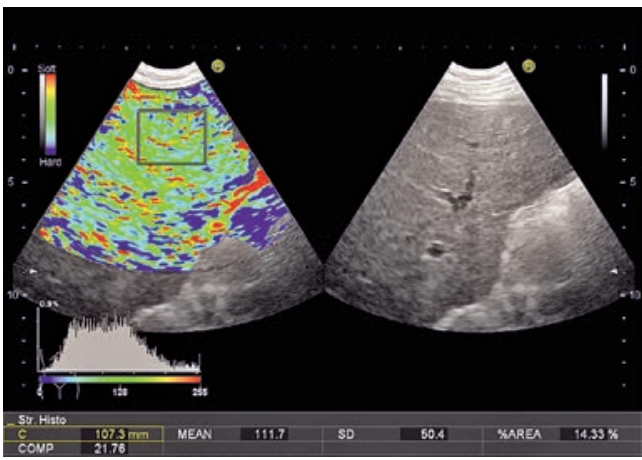

Fig 6. Strain Elastography with histogram

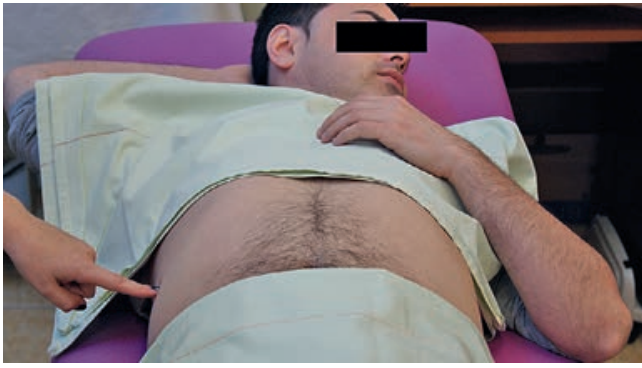

Fig 7. Patient position for elastographic evaluation

\section{Transient Elastography}

\section{Examination technique}

Liver stiffness measurements (LSMs) are performed in the right liver lobe, through the intercostal spaces, while the patient lies in a dorsal decubitus position with the right arm in maximal abduction (fig 7). The operator, assisted by ultrasound A-mode images provided by the system, locates a portion of the liver at least $6 \mathrm{~cm}$ thick and free of large vascular structures, then presses the probe button to begin an acquisition. Acquisitions that do not have a correct vibration shape or a correct follow-up of the vibration propagation are automatically rejected by the software. Measurements should be made in fasting conditions (since food intake increases LS values) [7,8], while the patient is holding breath to minimize errors [9].

To obtain reliable assessment it is recommended that at least 10 valid measurements should be obtained, with a success rate (SR) of at least $60 \%$ and an interquartile range (IQR) less than $30 \%$ of the median LSM value $[2,10]$. TE is considered failed if no valid shots can be obtained, and unreliable if fewer than 10 valid shots are obtained, or if 10 valid measurements are obtained, but with an IQR greater than $30 \%$, and/or a SR less than $60 \%$ [10].

Recently, new quality criteria for LS measurements were proposed [11], which increase the rate of reliable measurements, without affecting the accuracy of this method for non-invasive liver fibrosis assessment. According to these criteria, SR it is not longer a quality parameter and the measurements are classified in three categories: very reliable (IQR $\leq 10 \%$ ), reliable (IQR $=11$ $30 \%$ or IQR $>30 \%$ if LS $<7.1 \mathrm{kPa}$ ), and poorly reliable (IQR $>30 \%$ and $\mathrm{LS} \geq 7.1 \mathrm{kPa}$ ). The new poorly reliable are similar with the traditional unreliable measurements and should not be used in clinical practice.

\section{Feasibility and limitations}

Regarding the method's feasibility, using the standard M-probe, a Romanian study reported failure (no valid shots obtained) by TE in 2.2\% [12]. A large monocentric Romanian study revealed that from the 8218 patients included, failed and unreliable LSMs were observed in $29.2 \%$ of cases [13]. In multivariate analysis, age $>50$ years, BMI $>27.7 \mathrm{~kg} / \mathrm{m}^{2}$, weight $>77 \mathrm{~kg}$ and height $<$ $162 \mathrm{~cm}$ were significantly associated with non-success. This percentage was higher than the one observed in a French study (18.9\%) [10], who analyzed 13,369 TE measurements, possibly due to the higher mean BMI in the Romanian study (considering that higher BMI was associated with failed and unreliable LSM in both studies). Narrow intercostal spaces are also associated with lower feasibility in TE [14].

Technical solutions regarding the probe design were lately investigated, in order to overcome these limitations. A new probe (XL) became available, especially designed for obese patients, with a central frequency of $2.5 \mathrm{MHz}$ (compared with the $3.5 \mathrm{MHz}$ probe usually used). The XL probe is able to measure LS at a depth of $35-75 \mathrm{~mm}$ from the skin (while the normal $\mathrm{M}$ probe is able to do that only $25-45 \mathrm{~mm}$ deep). With the new transducer, in a French study it was possible to obtain valid measurements in approximately $60 \%$ of the patients with a BMI $\geq 30 \mathrm{~kg} / \mathrm{m}^{2}$, in which the M-probe failed to 
assess the LS [15]. In a Romanian study, in $63 \%$ of patients who could not be assessed with the standard $\mathrm{M}$ probe, valid measurements were obtained by means of the XL probe [16].

Liver fibrosis should not be assessed by TE in pregnant women and in patients with cardiac pacemaker [17].

\section{Reproducibility}

Published studies proved that TE is a highly reproducible method, with interobserver and intraobserver intraclass coefficient correlation ranging from 0.93 to 0.96 [9,18-20], with a very short learning curve - 50 examinations being required in order to obtain reliable measurements $[21,22]$. The study performed by Boursier et al also showed a high measurement agreement between novices and expert operators, even during the first 10 cases [22], so that a formal session by a qualified trainer, followed by practice on 50 cases, should suffice for the training of most operators.

Confounding factors

Even if TE is a non-invasive, highly reproducible method, it has some limitations. One of them is that it cannot be performed in patients with ascites [23].

Confounding factors identified to falsely increase the LS values are: high aminotransferases levels [24-28], congestive heart failure $[29,30]$, obstructive jaundice [31] and non-fasting conditions [7,8].

There are conflicting data regarding the influence of steatosis on LS measurements. Some studies state that the severity of hepatic steatosis does not appear to affect liver stiffness [32,33], while in the study of Lupşor et al, in univariant and multivariate analysis, steatosis influenced the LS values assessed by TE [34]. Nevertheless, in some studies, the proportion of patients with severe steatosis was too low to allow a definite quantification of its potential influence. Ziol et al [35] confirmed on a group of 152 patients, the fact that steatosis does indeed influence liver stiffness; this influence is negligible in cirrhotic patients, but is significant in patients without cirrhosis. However, a steatotic, non-inflamed liver seems to be usually softer, not stiffer. Further studies are therefore needed to explain how steatosis can influence liver stiffness.

Liver stiffness values by TE in healthy individuals

Regarding the normal LS values by TE, in a Romanian study that included 152 healthy subjects, the mean LS value was $4.8 \pm 1.3 \mathrm{kPa}$, ranging from 2.3 to $8.8 \mathrm{kPa}$. The mean LS values did not differ significantly among age groups and it was significantly lower in women than in men $(4.6 \pm 1.2 \mathrm{kPa}$ vs. $5.1 \pm 1.2 \mathrm{kPa}$, $\mathrm{p}=0.0082$ ) [36]. In two French studies performed on healthy subjects, the mean LS values were $5.49 \mathrm{kPa}$ [37] and $4.8 \mathrm{kPa}$ [38], respectively. In both studies LS values were higher in men than in women. Overall, the upper limit of normal LS was estimated to be $5.3 \mathrm{kPa}$ [37,39].

TE for liver fibrosis evaluation in chronic hepatitis $C$ patients

TE was firstly evaluated in patients with chronic hepatitis C. Romanian studies found the following cut-off values: for the diagnosis of mild fibrosis $(\mathrm{F} \geq 1)$ the cutoffs ranged between 4.9-5.3 $\mathrm{kPa}[34,40]$, for significant fibrosis ( $\mathrm{F} \geq 2$ Metavir) between 6.8-7.4 $\mathrm{kPa}[34,40,41]$, for severe fibrosis $(\mathrm{F} \geq 3)$ between $8.6-9.1 \mathrm{kPa}[34,40$, 42 ] and for liver cirrhosis $(\mathrm{F}=4)$ between $11.8-13.6 \mathrm{kPa}$ [34,40,42].

Several international meta-analyses assessed LS measurements by TE as a predictor of significant fibrosis ( $\mathrm{F} \geq 2$ Metavir) in patients with hepatitis C [43-46]. In the Friedrich-Rust meta-analysis, based on 50 studies [44], the mean AUROC was 0.84, with a suggested optimal cut-off of $7.6 \mathrm{kPa}$. In the Tsochatzis meta-analysis, the pooled cut-off for $\mathrm{F} \geq 2$ Metavir was also $7.6 \mathrm{kPa}$, with 0.78 pooled sensitivity and 0.89 pooled specificity [46].

Even if TE is not accurate enough to distinguish between contiguous stages of fibrosis, it can differentiate absence and mild fibrosis from significant fibrosis and cirrhosis, which is more critical for decisions regarding treatment [23] and thus it has been endorsed in the recommendations for the management of viral hepatitis by the European Association for the Study of the Liver [47].

$T E$ for liver fibrosis evaluation in chronic hepatitis $B$ patients

Several studies were published regarding the value of TE for predicting the severity of fibrosis in chronic hepatitis B patients, but with conflicting results regarding the cut-off values for different stages of fibrosis, probably due to the occurrence of aminotransferases flares in HBV patients (proven to falsely increase LS values). It has been suggested that an algorithm including ALT levels should be taken into consideration in those patients [23]. A Romanian study found similar mean LS values in patients with chronic hepatitis B and C [42]. A recent meta-analysis found considerable mean AUROCs for the diagnosis of significant fibrosis (F2) and cirrhosis (F4), namely of 0.859 and 0.929 , and the best cut-off values were $7.9 \mathrm{kPa}$ and $11.7 \mathrm{kPa}$, respectively [48]. The Tsochatzis meta-analysis also assessed the predictive value of LS assessed by TE in HBV patients. The pooled cut-off for $\mathrm{F} \geq 2$ Metavir was $7 \mathrm{kPa}$ (lower than in $\mathrm{HCV}$ patients), with 0.84 pooled sensitivity and 0.78 pooled specificity, while for predicting liver cirrhosis the pooled cut-off was $11.3 \mathrm{kPa}$, with 0.80 pooled Se and 0.89 pooled $\mathrm{Sp}[46]$. 


\section{TE for liver fibrosis evaluation in patients with NAFLD}

LS measurements can be difficult in patients with NAFLD, since they are often associated with obesity. A first step towards increasing the feasibility of TE in these patients was the introduction of the XL probe that increased the number of patients that could be evaluated by TE $[15,49,50]$. In a study by Lupşor et al in non-alcoholic steatohepatitis (NASH) patients, the cut-off values calculated for predicting each fibrosis stage were: $5.3 \mathrm{kPa}$ (AUROC $=0.879)$ for $\mathrm{F} 1,6.8 \mathrm{kPa}(\mathrm{AUROC}=0.789)$ for $\mathrm{F} 2$ and $10.4 \mathrm{kPa}$ (AUROC $=0.978$ ) for F3 [51]. In a study by Wong et al, the AUROCs of TE for $\mathrm{F} \geq 3$ was 0.93 , for a cut-off value of $7.9 \mathrm{kPa}$ [52].

TE for liver fibrosis evaluation in patients with various etiologies of liver disease

A meta-analysis published in 2011 [46], which included 40 studies, with more than 7,000 patients, obtained the following median values for $\mathrm{F}=1, \mathrm{~F}=2, \mathrm{~F}=3$ and $\mathrm{F}=4: 6$ $\mathrm{kPa}, 7.2 \mathrm{kPa}, 9.6 \mathrm{kPa}$ and $14.5 \mathrm{kPa}$, respectively.

Different cut-off values for the diagnosis of cirrhosis were proposed for different etiologies: $12.5 \mathrm{kPa}$ in $\mathrm{HCV}$ patients [53], $13.4 \mathrm{kPa}$ in $\mathrm{HBV}$ patients [54], $10.3 \mathrm{kPa}$ in NAFLD patients [52], $22.4 \mathrm{kPa}$ in alcoholic steatohepatitis (ASH) [55] and $17.3 \mathrm{kPa}$ in cholestatic chronic diseases (primary biliary cirrhosis and primary sclerosing colangitis) [56].

Noninvasive evaluation of liver steatosis using Controlled Attenuation Parameter (CAP)

Recently, TE manufacturer developed the CAP, which can quantify the severity of liver steatosis. Even though relatively few studies have been published on this topic, the preliminary results showed that CAP is a promising non-invasive tool to detect steatosis, with AUROCs of $0.80,0.86$ and 0.88 respectively, for predicting a fatty overload of more than $11 \%, 33 \%$, and $66 \%$, respectively [57]. Preliminary studies performed in Romania, have found significantly different CAP values for different steatosis grades and AUROCs of 0.830 and 0.85 respectively, for the prediction of a hepatic fat content over $33 \%$ and $66 \%$, respectively [58].

\section{TE for predicting liver cirrhosis complications}

Most studies assessing TE as a predictor of cirrhosis complications were performed regarding significant portal hypertension and esophageal varices (EV). In a Romanian study on 1,000 consecutive cirrhotic patients, for a cut-off value of $31 \mathrm{kPa}$ (chosen to maximize the sum of sensitivity and specificity), the negative and positive predictive values (NPV and PPV) for at least grade 2 esophageal varices (EV) were $76.2 \%$ and $71.3 \%$, respectively. If a PPV of more than $85 \%$ was searched for, the cut-off was $40 \mathrm{kPa}$, and if a NPV of $90 \%$ was aimed at, the cut-off value was $17.1 \mathrm{kPa}$ [59]. In the same study, for a cut-off value of $50.7 \mathrm{kPa}$, LS had $82.7 \%$ PPV and 53.6\% NPV (AUROC $=0.730$ ) for predicting esophageal bleeding. Published studies $[60,61]$ showed that cut-off values for predicting the presence of large EV are significantly higher in patients with alcoholic as compared with those with viral etiology of chronic liver disease. A meta-analysis which included 18 studies, with more than 3,500 patients [62], showed that TE had 0.90 summary senisitivity with 0.79 summary specificity (AUROC $=0.93$ ) for detecting the presence of clinically significant portal hypertension (HVPG $\geq 10 \mathrm{mmHg}$ ), 0.87 summary sensitivity with 0.53 summary specificity (AUROC $=0.84$ ) for predicting the presence of $\mathrm{EV}$ and 0.86 summary sensitivity and 0.59 summary specificity $(\mathrm{AUROC}=0.78$ ) for detecting large EV. Because of the low specificity of this method, LS assessed by TE cannot replace upper gastrointestinal endoscopy for EV screening in patients with liver cirrhosis.

LS assessed by TE can be used together with the simple serological Lok score, in order to increase the accuracy in detecting EV, as follows: if LS is $<19 \mathrm{kPa}$ and Lok score $<0.62$, the risk of EV is very low, while if LS is $>38 \mathrm{kPa}$ and the Lok score $>0.8$, the risk of large EV is very high [63].

Some studies also showed that TE may be useful for predicting the occurrence of hepatocellular carcinoma [64 - 66], but no application for these findings has been introduced into clinical practice until now.

\section{Point Shear Waves Elastography}

\section{a) Acoustic Radiation Force Impulse (ARFI) Elas- tography \\ Examination technique}

Liver stiffness (LS) measurements by means of ARFI elastography are performed using a convex 4CI transducer. The measurements are performed in fasting condition, with the patients in supine position, by intercostal approach, with minimal scanning pressure applied by the operator, usually the operator asking the patient to stop normal breathing for a moment, in order to minimize breathing motion. The operator places the ROI in a region without large vessels.

When ARFI technique appeared on the market, there were no recommendations regarding the number of measurements that should be performed, but now there is an agreement to perform 10 valid measurements and to calculate their median value as an indicator of LS. If for TE the manufacturer clearly recommended quality criteria parameters for LS measurements, for ARFI 
elastography there were no recommendations. Published studies $[67,68]$ demonstrated that the use of technical parameters $\mathrm{IQR}<30 \%$ and $\mathrm{SR} \geq 60 \%$ (but especially IQR) significantly increase the accuracy of this method, a fact also recognized by the manufacturer.

LS measurements should be performed at $1-2 \mathrm{~cm}$ under the liver capsule [69] and only in the right liver lobe, because the values obtained in the left liver lobe are significantly higher $[70,71]$. According to the acoustic window of the patient, the measurements can be performed either in segment $\mathrm{V}$ or in segment VIII, without affecting the results [66].

Feasibility, limitations and reproducibility

Ten valid LS measurements can be obtained in more than $96 \%$ of patients [72-76] and in approximately $93 \%$ of cases the measurements are valid (if quality parameters are applied) [76]. There is no published information regarding the learning curve for this method, but considering the excellent feasibility in published studies, probably there is no need for special training for physicians with basic knowledge of liver ultrasonography. Also, it has been demonstrated that ARFI elastography has good intra- and interoperator reproducibility for assessing LS $[77,78]$.

There is no information regarding the possibility to use this method in patients with cardiac pacemaker. Regarding the safety of this elastographic method in pregnant women there are published studies which assessed the placenta elasticity by means ARFI, with no complications reported $[79,80]$.

Confounding factors

Liver stiffness values assessed by ARFI elastography are falsely elevated if the patient is evaluated in postprandial condition [81,82], if the patient has elevated aminotransferases level $[83,84]$, or right heart failure [82]. Regarding the elevated aminotransferases level, ARFI elastography seems to be less influenced by moderately elevated values (between 2-5 times the upper limit of normal) as compared with TE [83].

Liver stiffness values by ARFI elastography in healthy volunteers

According to published data, LS values in Romanian healthy volunteers are $1.15 \pm 0.21 \mathrm{~m} / \mathrm{s}$, and they are not influenced by age and gender [85]. The other published studies showed that LS values in subjects without liver pathology ranged between 1.07 and $1.19 \mathrm{~m} / \mathrm{s}$ [86-90].

ARFI elastography for liver fibrosis evaluation in chronic hepatitis $C$ patients

Available data $[72,73,91]$, suggest that ARFI elastography has an excellent value for predicting different stages of liver fibrosis, the LS cut-offs in Romanian patients with chronic hepatitis $\mathrm{C}$ being: $\mathrm{F} \geq 1: 1.18-1.19 \mathrm{~m} / \mathrm{s}$
$($ AUROC $=0.70-0.88), \mathrm{F} \geq 2: 1.21-1.34 \mathrm{~m} / \mathrm{s}($ AUROC $=$ $0.85-0.90), \mathrm{F} \geq 3: 1.54-1.61 \mathrm{~m} / \mathrm{s}($ AUROC $=0.87-0.99)$ and $\mathrm{F}=4: 1.82-2 \mathrm{~m} / \mathrm{s}(\mathrm{AUROC}=0.91-0.99)$.

ARFI elastography for liver fibrosis evaluation in chronic hepatitis $B$ patients

Published data showed similar correlation with histological liver fibrosis in Romanian patients with chronic hepatitis $\mathrm{B}$ and $\mathrm{C}$ and also that the mean LS values for each stage of fibrosis were similar for these two categories of patients [92].

ARFI elastography for liver fibrosis evaluation in NAFLD

ARFI elastography had a good value to discriminate between patients with simple steatosis and those with non-alcoholic steatohepatitis, for a cut-off value of $>1.10$ $\mathrm{m} / \mathrm{s}($ AUROC $=0.86)$ [75]. Also, ARFI elastography had a good value for predicting different stages of liver fibrosis, in a cohort of Romanian patients with non-alcoholic liver disease, but the cut-off values were lower as compared with chronic hepatitis patients: $\mathrm{F} \geq 1: 1.10 \mathrm{~m} / \mathrm{s}$ $(A U R O C=0.86), F \geq 2: 1.16 \mathrm{~m} / \mathrm{s}(A U R O C=0.94), \mathrm{F} \geq 3$ : $1.48 \mathrm{~m} / \mathrm{s}($ AUROC $=0.98)$ and $\mathrm{F}=4: 1.63 \mathrm{~m} / \mathrm{s}($ AUROC $=0.98)$ [75].

ARFI elastography for liver fibrosis evaluation in a cohort of patients with various etiologies of liver disease

In a bicentric Romanian study [74], which included patients with viral and non-viral etiology of chronic liver disease, the best cut-offs values for predicting the presence of significant fibrosis $(\mathrm{F} \geq 2)$ and liver cirrhosis $(\mathrm{F}=4)$ were: $1.27 \mathrm{~m} / \mathrm{s}($ AUROC $=0.89)$ and $1.7 \mathrm{~m} / \mathrm{s}($ AU$\mathrm{ROC}=0.93$ ), respectively.

A meta-analysis published in 2013 [93] including 3,951 patients from 36 studies, also showed a good performance of ARFI elastography for non-invasive assessment of liver fibrosis. The best LS cut-off values $(\mathrm{m} / \mathrm{s})$ for predicting $\mathrm{F} \geq 2, \mathrm{~F} \geq 3$ and $\mathrm{F}=4$ were: $1.35 \mathrm{~m} / \mathrm{s}, 1.61 \mathrm{~m} / \mathrm{s}$ and $1.87 \mathrm{~m} / \mathrm{s}$, respectively and the AUROC curves were: $0.84,0.89$ and 0.91 , respectively.

Another meta-analysis published in 2013 [94], which included patients evaluated both by TE and ARFI elastography considering liver biopsy as the "goldstandard" method, showed that inability to obtain reliable measurements was more than thrice as high for TE as for ARFI elastography $(6.6 \%$ vs. $2.1 \%, p<0.0001)$. For predicting the presence of significant fibrosis and liver cirrhosis, both elastographic techniques had similar values.

The usefulness of ARFI elastography for predicting the complications of liver cirrhosis

The separate use of LS or spleen stiffness (SS) has limited value for predicting the presence of significant EV (at least grade 2) in Romanian patients with liver cir- 
rhosis, with AUROC curves of approximately 0.60 [95]. These results are in line with European studies [96], and different from Asian studies [97,98], which showed that especially spleen stiffness can be useful for predicting the presence of EV.

Prediction of significant EV can be found by combining LS and SS using the following formula: Pred $\mathrm{EV}_{2-3}=$ $-0.572+0.041 \times \operatorname{LS}(\mathrm{m} / \mathrm{s})+0.122 \times \mathrm{SS}(\mathrm{m} / \mathrm{s})+0.325 \mathrm{x}$ ascites (1-absent, 2-present). For a cut-off value $>0.395$, the accuracy of ARFI elastography for predicting the presence of significant EV can be increased to $70 \%$, but not enough to replace upper gastrointestinal endoscopy in daily clinical practice [95].

ARFI elastography has also limited value for predicting the decompensation of liver cirrhosis (AUROC around 0.60) [99] and seems to not be useful for predicting the occurrence of hepatocellular carcinoma [100].

\section{b) ElastPQ technique}

Examination technique

The measurements are performed on patients in supine position, with minimal scanning pressure applied by the operator, usually the operator asking the patient to stop normal breathing for a moment, in order to minimize breathing motion. The operator places the ROI in a region without large vessels. There is no information regarding if the measurements must be made under fasting conditions. Also, there are no published studies, nor information from the manufacturer regarding the use of some quality criteria parameters for LS measurements assessed by means of this technique.

According to published data [101], LS measurements by ElastPQ should be performed in the liver segment V, because the lowest variation of LS measurements was observed in this location.

\section{Feasibility and reproducibility}

Ten valid LS measurements can be obtained in more than $95 \%$ of patients [101-103]. There is no information about the learning curve of this method, but similar with ARFI elastography, considering the excellent feasibility in the few published studies, probably a special training is not needed for physicians with basic knowledge in liver ultrasonography. A good inter-operator reproducibility was observed for this technique [102].

\section{Confounding factors}

Very few information are available to date, but it seems that increased necroinflammatory activity is associated with higher values of LS by ElastPQ [102].

Liver stiffness values in healthy volunteers

According to available data, LS values by ElastPQ in Romanian healthy volunteers are $1.08 \pm 0.12 \mathrm{~m} / \mathrm{s}$, value equivalent with $3.5 \pm 0.04 \mathrm{kPa}$ [103]. An Asian study showed that LS values by ElastPQ technique are significantly higher in men as compared with women and that they are not influenced by age [102].

Elast $P Q$ technique for liver fibrosis evaluation in chronic hepatitis $C$ patients

No information available until now.

ElastPQ technique for liver fibrosis evaluation in chronic hepatitis $B$ patients

Published data showed a good value of ElastPQ technique for predicting the presence of significant fibrosis $(\mathrm{F} \geq 2)$ and cirrhosis $(\mathrm{F}=4)$, the best LS cut-off values being: $6.99 \mathrm{kPa}(\mathrm{AUROC}=0.94)$ and $9 \mathrm{kPa}(\mathrm{AUROC}=0.89)$, respectively [102].

Elast $P Q$ technique for liver fibrosis evaluation in a cohort of patients with both chronic hepatitis $B$ and $C$

In a cohort of patients with both viral etiologies of chronic liver disease, the median LS values for different stages of liver fibrosis were: $\mathrm{F} 0-1=4.6 \mathrm{kPa}, \mathrm{F} 2=5.9$ $\mathrm{kPa}, \mathrm{F} 3=7 \mathrm{kPa}$ and $\mathrm{F} 4=12 \mathrm{kPa}$, respectively [104]. Also, ElastPQ technique had similar value with TE for predicting different stages of liver fibrosis.

The usefulness of Elast $P Q$ technique for predicting the complications of liver cirrhosis

No information available until now.

\section{D Shear Waves Elastography (2D-SWE)}

\section{Examination technique}

For this technique a SC6-1convex probe is used. The measurements are performed in fasting condition, with the patients in supine position, by intercostal approach in the right liver lobe. Usually the operator is asking the patient to stop normal breathing for a few seconds, in order to minimize breathing motion. The operator places the region of interest in an area without large vessels, at a depth more than $2 \mathrm{~cm}$, but no further than $8 \mathrm{~cm}$. Until now, there is no consensus regarding the number of measurements that should be performed, three [105], four [106] or five [107-109] valid 2D- SWE measurements were performed in different studies. Also, some studies used the mean value of LS measurements $[105,106]$, while in others the median was used [109]. A Romanian study [110] showed that the mean LS values and their correlation with TE values are similar if the mean value of three, mean value of five or median value of five valid 2D-SWE measurements was used. There are no quality criteria recommended by the manufacturer nor by published studies regarding LS measurements by $2 \mathrm{D}-\mathrm{SWE}$.

Feasibility, limitations and reproducibility

Most published studies showed that three/five LS measurements by means of 2D-SWE can be obtained in 
$90-98.9 \%$ of cases $[105,106,111,112]$. If the same quality criteria as in TE are applied (IQR $<30 \%$ and $\mathrm{SR} \geq 30 \%$ ), the rate of reliable measurements can decrease to $71.3 \%$ [109]. It was demonstrated that the intra- and inter-observer reproducibility of 2D-SWE is very good in assessing LS [111,113], but previous experience in ultrasound increases the rate of valid measurements, especially in obese patients [114]. Also, the narrow intercostal spaces are associated with impossibility to obtain valid LSMs [106].

There is no information regarding the safety of this elastographic method in patients with cardiac pacemakers, nor in pregnant women.

Confounding factors

It was demonstrated that, similar to other ultrasound based elastographic methods, non-fasting condition is associated with falsely elevated LS values [115]. There are no available information regarding the influence of elevated aminotransferases level, congestive heart failure or obstructive jaundice.

Liver stiffness values in healthy volunteers

A Romanian study [116] showed that the mean LS in healthy volunteers is $6 \pm 1.4 \mathrm{kPa}$ (median $5.7 \mathrm{kPa}$ ), higher values being obtained in men as compared to women $(6.6 \pm 1.5 \mathrm{kPa}$ vs. $5.7 \pm 1.3 \mathrm{kPa}, \mathrm{p}=0.01$.

$2 D$-SWE for liver fibrosis evaluation in chronic hepatitis $C$ patients

Published data available in this moment suggest that 2D-SWE is a good, reliable method for assessing LS in chronic hepatitis $C$ patients [106], the best-off values for different stages of liver fibrosis being: $\mathrm{F} \geq 2: 7.1 \mathrm{kPa}$ (AU$\mathrm{ROC}=0.92), \mathrm{F} \geq 3: 8.7 \mathrm{kPa}(\mathrm{AUROC}=0.98)$ and $\mathrm{F} 4: 10.4$ $\mathrm{kPa}($ AUROC $=0.98)$.

2D-SWE for liver fibrosis evaluation in chronic hepatitis $B$ patients

Published data regarding LS assessment by means of 2D-SWE in patients with chronic hepatitis B, are quite similar to those regarding chronic hepatitis $\mathrm{C}$ patients: $\mathrm{F} \geq 1: 6.5 \mathrm{kPa}$ (AUROC $=0.86$ ), $\mathrm{F} \geq 2: 7.1 \mathrm{kPa}$ (AU$\mathrm{ROC}=0.88), \mathrm{F} \geq 3: 7.9 \mathrm{kPa}(\mathrm{AUROC}=0.93)$ and $\mathrm{F} 4: 10.1$ $\mathrm{kPa}(\mathrm{AUROC}=0.98)$ [105].

$2 D$-SWE for liver fibrosis evaluation in a cohort of patients with various etiologies of liver disease

According to published data on Romanian patients with various etiologies of chronic liver disease the following cut-off values were established for predicting each degree of fibrosis: $\mathrm{F} \geq 1: 7.1 \mathrm{kPa}$ (AUROC $=0.825$ ), $\mathrm{F} \geq 2$ : $7.8 \mathrm{kPa}($ AUROC $=0.859), \mathrm{F} \geq 3: 8 \mathrm{kPa}($ AUROC $=0.897)$ and for $\mathrm{F}=4: 11.5 \mathrm{kPa}$ (AUROC=0.914) [117].

The usefulness of 2D-SWE for predicting the complications of liver cirrhosis

No information available until now.

\section{Strain Elastography}

Even though strain elastography is available on many US imaging devices from Siemens, GE, Aloka and Toshiba, this approach emphasizes the Real-Time Strain Elastography (RT-E) from Hitachi, as the first method used in clinical practice and also with the majority of published studies.

\section{Examination technique}

The ultrasound probe can be placed either in a right intercostal space for the right hepatic lobe or in the epigastric region for the left lobe of the liver [118].

The following requirements are necessary in order to obtain high quality elastography images [119]: high quality US images, without rib shadows, should be obtained; RT-E images must be displayed periodically, based on compressions induced by cardiac/vascular motion and not by applying an external pressure with the ultrasound probe; the RT-E image is obtained during breath holding at the end-expiration phase; the region of interest (ROI) must not contain large blood vessels; ROI should be placed at a certain distance from the surface of the liver (displayed in blue, due to multiple reflection echoes).

Feasibility and reproducibility

Ultrasound examinations are operator-dependent techniques and different levels of training and experience could influence the results of the real-time elastography as well. A prospective study in which patients were examined by two physicians with different levels of experience in ultrasound, obtained good intra- and inter-observer variability values [120]. The authors did not find statistically significant difference between the two physicians, regardless of the patients' real status (cirrhosis, chronic hepatitis, steatosis, or healthy subjects). In a study published by Koizumi et al, elastography was performed at four liver locations by two independent observers. The authors found no difference in reproducibility for the four measurement positions, while the interobserver agreement was very good $(\mathrm{k}=95 \%)$ [121].

\section{Confounding factors}

No information available until now.

\section{Pitfalls and limitations}

In the presence of a very soft (highly elastic) structure, like the hepatic vein or ascites, the rest of the liver would be depicted as hard in RT-E, irrespective of its elasticity (strain) [122]. The area nearby ribs or near the surface of the liver may also induce artifacts, displayed in blue on RT-E images. The presence of ascites does not appear to significantly influence the resu are still ongoing studies lts of real-time elastography [123].

Another important limitation of liver RT-E is the depth of penetration. The penetration of real-time elas- 
tography performed with a linear probe was limited in the first software versions to $3-4 \mathrm{~cm}$, with a relatively difficult recording of useful elastography information inside the liver, when the chest wall was thicker than 2-3 cm. Latest US systems (Hitachi Preirus / Avius / Ascendus) allow measurements at much deeper sites by using a convex probe when performing elastography, as well as an almost entire examination of the liver.

Although it is not clear if strain histograms or strain ratios should be used for quantification of RT-E information, phantom studies clearly showed that both quantitative techniques are superior to qualitative visual scorings, in order to assess target stiffness [124]. Target size was shown to have a significant impact on visual scorings and strain ratios, although it does not seem to influence strain histograms. Also, observer experience had a significant effect on visual scorings, but not on strain histograms or strain ratios [124].

Liver stiffness values in healthy volunteers

No information available until now.

RT-E for liver fibrosis evaluation in chronic hepatitis $C$ patients

Unlike the other elastographic methods, the recording method and analysis of data obtained by RT-E was variable, depending on the published studies. Consequently, due to the heterogenity of published data, further studies should clarify the value of RT-E, as well as the optimal cut-offs used to differentiate different stages of liver fibrosis.

According to previously published data, the optimal elastic ratio cut-off values (the ratio of the value of small intrahepatic veins/ the value of hepatic parenchyma) are 2.73 for $F \geq 2,3.25$ for $F \geq 3$ and 3.93 for $F=4$ [121]. Another group showed a significant correlation between the elastic ratio of the liver for the intercostal muscle and the histological fibrosis stage. A higher elastic ratio indicated softer hepatic elasticity. The median liver elastic ratios were 1.56 for F0, 1.36 for F1, 0.62 for F3 and 0.45 for F4 [125].

When the average strain histogram was calculated, the RT-E accuracy increased with fibrosis stage, from $77 \%$ for $\mathrm{F} \geq 2$, to $94 \%$ for $\mathrm{F}=4$ [126]. Another study published by Morikawa et al., showed a good performance of the mean histogram in the prediction of fibrosis stage: the AUROCs were 0.93 for $\mathrm{F} \geq 3$ and 0.91 for cirrhosis [127].

In a recent multicentre study, a new score was calculated from strain elastography images - Liver Fibrosis Index (LFI), with the best cut-off of 2.05 for $\mathrm{F} \geq 2$ (AU$\mathrm{ROC}=0.73$ ), 2.28 for $\mathrm{F} \geq 3$ (AUROC $=0.796$ ) and 2.36 for $\mathrm{F}=4(\mathrm{AUROC}=0.783)[128]$.
$R$-TE for liver fibrosis evaluation in chronic hepatitis $B$ patients

The optimal Elasticity Index cut-off values for the diagnosis of fibrosis stages in chronic hepatitis $\mathrm{B}$ patients were 20.94 for $\mathrm{F} \geq 1$ (AUROC $=0.93$ ), 55.33 for $\mathrm{F} \geq 2$ (AU$\mathrm{ROC}=0.92), 80.71$ for $\mathrm{F} \geq 3$ (AUROC $=0.84$ ) and 90.31 for $\mathrm{F}=4(\mathrm{AUROC}=0.66)[129]$.

The usefulness of RT-E for predicting liver cirrhosis complication

No information available until now.

\section{Ultrasound based elastography for the evaluation of focal liver lesions}

Several studies have been published regarding the usefulness of ultrasound based elastography for the evaluation of focal liver lesions [130-133] and even one meta-analysis [134]. Nevertheless, in this moment, this method is not recommended for daily clinical use. There are still ongoing studies trying to find the right place of elastography for focal liver lesions assessment.

In Table I are summarized, for each elastographic method, the information regarding the position for LS evaluation, confounding factors, mean LS values in healthy volunteers, the best LS cut-offs values for predicting different stages of liver fibrosis for chronic hepatitis $\mathrm{B}$ or $\mathrm{C}$ patients and also for NAFLD patients. The informations are from Romanian published studies; other published sources were used where no Romanian published author were available.

\section{Conclusions}

US based elastography of the liver is a developing method, which will probably replace many liver biopsies. TE is a validated method, especially in chronic viral hepatitis, being included in the EASL Guidelines for fibrosis assessment in chronic B and $\mathrm{C}$ hepatitis. Point SWE (especially ARFI) has been proven to be non-inferior and more feasible as compared to TE, for fibrosis assessment in patients with chronic liver disease. 2D-SWE showed promising results for the evaluation of patients with chronic hepatitis. Regarding RT-E, further research is still needed, in order to find the optimal technical approach for liver stiffness assessment. None of the elastographic methods has enough accuracy in order to be included in clinical practice as screening method for liver cirrhosis complications, such as esophageal varices or hepatocellular carcinoma occurrence.

Conflict of interest: none 
Table I. The main information for each elastographic technique about position for liver stiffness evaluation, confounding factors, mean liver stifness in healthy volunteers and cut-off values for different stages of liver fibrosis for different etiologies of chronic liver disease

\begin{tabular}{|c|c|c|c|c|c|}
\hline & TE & ARFI & ElastPQ & 2D-SWE & RT-E \\
\hline Patient position & Supine & Supine & Supine & Supine & Supine \\
\hline $\begin{array}{l}\text { Confounding } \\
\text { factors }\end{array}$ & $\begin{array}{l}\text {-non-fasting condi- } \\
\text { tion } \\
\text {-high AT levels } \\
\text {-CHF } \\
\text {-obstructive jaun- } \\
\text { dice } \\
\text {-contradictory data } \\
\text { on steatosis }\end{array}$ & $\begin{array}{l}\text {-non-fasting condi- } \\
\text { tion } \\
\text {-high AT levels } \\
\text {-CHF }\end{array}$ & $\begin{array}{l}\text {-no clear available } \\
\text { information }\end{array}$ & $\begin{array}{l}\text {-non-fasting condi- } \\
\text { tion } \\
\text {-no others informa- } \\
\text { tion available }\end{array}$ & $\begin{array}{l}\text {-no available infor- } \\
\text { mation }\end{array}$ \\
\hline $\begin{array}{l}\text { Healthy volun- } \\
\text { teers values }\end{array}$ & $4.6-5.5 \mathrm{kPa}$ & $1.07-1.19 \mathrm{~m} / \mathrm{s}$ & $\sim 3.5 \mathrm{kPa}$ & $\sim 5.7 \mathrm{kPa}$ & $\begin{array}{l}\text {-no available infor- } \\
\text { mation }\end{array}$ \\
\hline HCV cut-offs & $\begin{array}{l}-\mathrm{F} \geq 1: 4.9-5.3 \mathrm{kPa} \\
-\mathrm{F} \geq 2: 6.8-7.4 \mathrm{kPa} \\
-\mathrm{F} \geq 3: 8.6-9.1 \mathrm{kPa} \\
-\mathrm{F}=4: 11.8-13.6 \mathrm{kPa}\end{array}$ & $\begin{array}{l}-\mathrm{F} \geq 1: 1.18-1.19 \mathrm{~m} / \mathrm{s} \\
-\mathrm{F} \geq 2: 1.21-1.34 \mathrm{~m} / \mathrm{s} \\
-\mathrm{F} \geq 3: 1.54-1.61 \mathrm{~m} / \mathrm{s} \\
-\mathrm{F}=4: 1.81-2 \mathrm{~m} / \mathrm{s}\end{array}$ & No available data & $\begin{array}{l}-\mathrm{F} \geq 1: \text { No data } \\
-\mathrm{F} \geq 2: 7.1 \mathrm{kPa} \\
-\mathrm{F} \geq 3: 8.7 \mathrm{kPa} \\
-\mathrm{F}=4: 10.4 \mathrm{kPa}\end{array}$ & $\begin{array}{l}E R: \\
-F \geq 1: \text { No data } \\
-F \geq 2: 2.73 \\
-F \geq 3: 3.25 \\
-F=4: 3.93 \\
L F I: \\
-F \geq 1: \text { No data } \\
-F \geq 2: 2.05 \\
-F \geq 3: 2.28 \\
-F=4: 2.36\end{array}$ \\
\hline HBV cut-offs & $\begin{array}{l}-\mathrm{F} \geq 1: \text { No clear data } \\
-\mathrm{F} \geq 2: 7-7.9 \mathrm{kPa} \\
-\mathrm{F} \geq 3: 8.2-8.8 \mathrm{kPa} \\
-\mathrm{F}=4: 11.3-11.7 \mathrm{kPa}\end{array}$ & $\begin{array}{l}\text { Similar mean LS } \\
\text { values for chronic } \\
\text { hepatitis B and C } \\
\text { patients }\end{array}$ & $\begin{array}{l}-\mathrm{F} \geq 1: \text { No data } \\
-\mathrm{F} \geq 2: 6.99 \mathrm{kPa} \\
-\mathrm{F} \geq 3: \mathrm{No} \text { data } \\
-\mathrm{F}=4: 9 \mathrm{kPa}\end{array}$ & $\begin{array}{l}-\mathrm{F} \geq 1: 6.5 \mathrm{kPa} \\
-\mathrm{F} \geq 2: 7.1 \mathrm{kPa} \\
-\mathrm{F} \geq 3: 7.9 \mathrm{kPa} \\
-\mathrm{F}=4: 10.1 \mathrm{kPa}\end{array}$ & $\begin{array}{l}\text { Elasticity index: } \\
-\mathrm{F} \geq 1: 20.94 \\
-\mathrm{F} \geq 2: 55.33 \\
-\mathrm{F} \geq 3: 80.71 \\
-\mathrm{F}=4: 90.31\end{array}$ \\
\hline $\begin{array}{l}\text { NAFLD cut- } \\
\text { offs }\end{array}$ & $\begin{array}{l}-\mathrm{F} \geq 1: 5.3 \mathrm{kPa} \\
-\mathrm{F} \geq 2: 6.8 \mathrm{kPa} \\
-\mathrm{F} \geq 3: 10.4 \mathrm{kPa} \\
-\mathrm{F}=4: 11.5 \mathrm{kPa}\end{array}$ & $\begin{array}{l}-\mathrm{F} \geq 1: 1.10 \mathrm{~m} / \mathrm{s} \\
-\mathrm{F} \geq 2: 1.16 \mathrm{~m} / \mathrm{s} \\
-\mathrm{F} \geq 3: 1.48 \mathrm{~m} / \mathrm{s} \\
-\mathrm{F}=4: 1.63 \mathrm{~m} / \mathrm{s}\end{array}$ & No available data & No available data & $\begin{array}{l}\text { No clear available } \\
\text { data }\end{array}$ \\
\hline
\end{tabular}

TE- Transient Elastography; ARFI- Acoustic Radiation Force Impulse Elastography; 2D-SWE- Two-dimensional Shear Wave Elastography; RT-E- Real Time Elastography; AT- aminotransferases; CHF- congestive heart failure; ER- Elastic Ratio; LFI- Liver Fibrosis Index; NAFLD- non-alcoholic fatty liver disease

\section{References}

1. Bamber J, Cosgrove D, Dietrich CF, et al. EFSUMB guidelines and recommendations on the clinical use of ultrasound elastography. Part 1: Basic principles and technology. U1traschall Med 2013; 34: 169-184.

2. Sandrin L, Fourquet B, Hasquenoph JM, et al. Transient elastography: a new noninvasive method for assessment of hepatic fibrosis. Ultrasound Med Biol 2003; 29: 1705-1713.

3. Palmeri ML, Wang MH, Dahl JJ, Frinkley KD, Nightingale KR. Quantifying hepatic shear modulus in vivo using acoustic radiation force. Ultrasound Med Biol 2008; 34: 546-558.

4. Bercoff J, Tanter M, Muller M, Fink M. The role of viscosity in the impulse diffraction field of elastic waves induced by the acoustic radiation force. IEEE Trans Ultrason Ferroelectr Freq Control 2004; 51: 1523-1536.
5. Muller M, Gennisson JL, Deffieux T, Tanter M, Fink M. Quantitative viscoelasticity mapping of human liver using supersonic shear imaging: preliminary in vivo feasibility study. Ultrasound Med Biol 2009; 35: 219-229.

6 . Frey H. Realtime elastography. A new ultrasound procedure for the reconstruction of tissue elasticity. Radiologe 2003;43:850-855.

7. Mederacke I, Wursthorn K, Kirschner J, et al. Food intake increases liver stiffness in patients with chronic or resolved hepatitis C virus infection. Liver Int 2009; 29: 1500-1506.

8. Arena U, Lupsor Platon M, Stasi C, et al. Liver stiffness is influenced by a standardized meal in patients with chronic hepatitis $\mathrm{C}$ virus at different stages of fibrotic evolution. Hepatology 2013;58: 65-72.

9. Boursier J, Konate A, Gorea G, et al. Reproducibility of liver stiffness measurement by ultrasonographic elastometry. Clin Gastroenterol Hepatol 2008; 6: 1263-1269. 
10. Castera L, Foucher J, Bernard PH, et al. Pitfalls of liver stiffness measurement: a 5-year prospective study of 13,369 examinations. Hepatology 2010; 51: 828-835.

11. Boursier J, Zarski JP, de Ledinghen V, et al; Multicentric Group from ANRS/HC/EP23 FIBROSTAR Studies. Determination of reliability criteria for liver stiffness evaluation by transient elastography. Hepatology 2013; 57: 11821191.

12. Lupşor Platon M, Ștefănescu H, Feier D, Maniu A, Badea R. Performance of unidimensional transient elastography in staging chronic hepatitis C. Results from a cohort of 1,202 biopsied patients from one single center. J Gastrointestin Liver Dis 2013; 22: 157-166.

13. Şirli R, Sporea I, Bota S, Jurchiş A. Factors influencing reliability of liver stiffness measurements using transient elastography (M-probe)-monocentric experience. Eur J Radiol 2013; 82: e313-e316.

14. de Lédinghen V, Vergniol J. Transient elastography (FibroScan). Gastroenterol Clin Biol 2008; 32(6 Suppl 1): 58-67.

15. de Lédinghen V, Vergniol J, Foucher J, El-Hajbi F, Merrouche W, Rigalleau V. Feasibility of liver transient elastography with FibroScan using a new probe for obese patients. Liver Int 2010; 30: 1043-1048.

16. Şirli R, Sporea I, Deleanu A, et al. Comparison between the $\mathrm{M}$ and $\mathrm{XL}$ probes for fibrosis assessment by Transient Elastography (TE). EPOS ECR 2014, DOI:10.1594/ECR2014/C-1145, http://dx.doi.org/10.1594/ ecr2014/C-1145.

17. Del Poggio P, Colombo S. Is transient elastography a useful tool for screening liver disease? World J Gastroenterol 2009; 15: 1409-1414.

18. Deleanu A, Şirli R, Popescu A, et al. Feasability, accuracy and reproducibility of transient elastography. Med Ultrason 2009; 11: 31-35.

19. Fraquelli M, Rigamonti C, Casazza G, et al. Reproducibility of transient elastography in the evaluation of liver fibrosis in patients with chronic evaluation of liver fibrosis in patients with chronic liver disease. Gut 2007: 56; 968-973.

20. Nobili V, Vizzutti F, Arena U, et al. Accuracy and reproducibility of transient elastography for the diagnosis of fibrosis in pediatric nonalcoholic steatohepatitis. Hepatology 2008; 48: 442-448.

21. Kettaneh A, Marcellin P, Douvin C, et al. Features associated with success rate and performance of FibroScan measurements for the diagnosis of cirrhosis in HCV patients: a prospective study of 935 patients. J Hepatol 2007; 46: 628-634.

22. Boursier J, Konate A, Guilluy M, et al. Learning curve and interobserver reproducibility evaluation of liver stiffness measurement by transient elastography. Eur J Gastroenterol Hepatol 2008; 20: 693-701.

23. Cosgrove D, Piscaglia F, Bamber J, et al. EFSUMB guidelines and recommendations on the clinical use of ultrasound elastography. Part 2: Clinical applications. Ultraschall Med 2013; 34: 238-253.

24. Coco B, Oliveri F, Maina AM, et al. Transient elastography: a new surrogate marker of liver fibrosis influenced by major changes of transaminases. J Viral Hepat 2007; 14: 360-369.

25. Viganò M, Massironi S, Lampertico P, et al. Transient elastography assessment of the liver stiffness dynamics during acute hepatitis B. Eur J Gastroenterol Hepatol 2010; 22: 180-184.

25. Chan HL, Wong GL, Choi PC, et al. Alanine aminotransferase-based algorithms of liver stiffness measurement by transient elastography (FibroScan) for liver fibrosis in chronic hepatitis B. J Viral Hepat 2009; 16: 36-44.

27. Sagir A, Erhardt A, Schmitt M, Haussinger D. Transient elastography is unreliable for detection of cirrhosis in patients with acute liver damage. Hepatology 2008; 47: 592595.

28. Arena U, Vizzutti F, Corti G, et al. Acute viral hepatitis increases liver stiffness values measured by transient elastography. Hepatology 2008; 47: 380-384.

29. Millonig G, Friedrich S, Adolf S, et al. Liver stiffness is directly influenced by central venous pressure. J Hepatol 2010; 52: 206-210.

30. Colli A, Pozzoni P, Berzuini A, et al. Decompensated chronic heart failure: increased liver stiffness measured by means of transient elastography. Radiology 2010; 257: 872878.

31. Millonig G, Reimann FM, Friedrich S, et al. Extrahepatic cholestasis increases liver stiffness (FibroScan) irrespective of fibrosis. Hepatology 2008; 48: 1718-1723.

32. Arena U, Vizzutti F, Abraldes JG, et al. Reliability of transient elastography for the diagnosis of advanced fibrosis in chronic hepatitis C. Gut 2008; 57: 1288-1293.

33. Wong VW, Vergniol J, Wong GL, et al. Diagnosis of fibrosis and cirrhosis using liver stiffness measurement in nonalcoholic fatty liver disease. Hepatology 2010; 51: 454-462.

34. Lupşor M, Badea R, Stefănescu H, et al. Analysis of histopathological changes that influence liver stiffness in chronic hepatitis C. Results from a cohort of 324 patients. J Gastrointestin Liver Dis 2008; 17: 155-163.

35. Ziol M, Kettaneh A, Ganne-Carrié N, Barget N, TengherBarna I, Beaugrand M. Relationships between fibrosis amounts assessed by morphometry and liver stiffness measurements in chronic hepatitis or steatohepatitis. Eur J Gastroenterol Hepatol 2009;21: 1261-1268.

36. Şirli R, Sporea I, Tudora A, Deleanu A, Popescu A. Transient elastographic evaluation of subjects without known hepatic pathology: does age change the liver stiffness? J Gastrointestin Liver Dis 2009; 18: 57-60.

37. Roulot D, Czernichow S, Le Clésiau H, Costes JL, Vergnaud AC, Beaugrand M. Liver stiffness values in apparently healthy subjects: influence of gender and metabolic syndrome. J Hepatol 2008; 48: 606 -613.

38. Corpechot C, El Naggar A, Poupon R. Gender and liver: is the liver stiffness weaker in weaker sex? Hepatology 2006; 44: 513-514.

39. Kim SU, Choi GH, Han WK et al. What are "true normal" liver stiffness values using FibroScan?: a prospective study in healthy living liver and kidney donors in South Korea. Liver Int 2010; 30: 268-274. 
40. Lupșor Platon M, Stefănescu H, Feier D, Maniu A, Badea R. Performance of unidimensional transient elastography in staging chronic hepatitis C. Results from a cohort of 1,202 biopsied patients from one single center. J Gastrointestin Liver Dis 2013; 22: 157-166.

41. Sporea I, Sirli R, Deleanu A, et al. Comparison of the liver stiffness measurement by transient elastography with the liver biopsy. World J Gastroenterol 2008; 14: 6513-6517.

42. Sporea I, Şirli R, Deleanu A, et al. Liver stiffness measurements in patients with HBV vs HCV chronic hepatitis: a comparative study. World J Gastroenterol 2010; 16: 48324837.

43. Talwalkar JA. Kurtz DM, Schoenleber SJ, West CP, Montori VM. Ultrasound-based transient elastography for the detection of hepatic fibrosis: systematic review and metaanalysis. Clin Gastroenterol Hepatol 2007; 5: 1214-1220.

44. Friedrich-Rust M, Ong MF, Martens S, et al. Performance of transient elastography for the staging of liver fibrosis: a meta-analysis. Gastroenterology 2008; 134: 960-974.

45. Shaheen AA, Wan AF, Myers RP. FibroTest and FibroScan for the prediction of hepatitis C-related fibrosis: a sytematic review of diagnostic test accuracy. Am J Gastroenterol 2007; 102: 2589-2600.

46. Tsochatzis EA, Gurusamy KS, Ntaoula S, Cholongitas E, Davidson BR, Burroughs AK. Elastography for the diagnosis of severity of fibrosis in chronic liver disease: a meta-analysis of diagnostic accuracy. J Hepatol 2011; 54: 650-659.

47. European Association for the Study of the Liver. EASL Clinical Practice Guidelines: Management of hepatitis C virus infection. J Hepatol 2011; 55: 245-264.

48. Chon YE, Choi EH, Song KJ, et al. Performance of transient elastography for the staging of liver fibrosis in patients with chronic hepatitis B: a meta-analysis. PLoS One 2012; 7: e44930.

49. Myers RP, Pomier-Layrargues G, Kirsch R, et al. Feasibility and diagnostic performance of the FibroScan XL probe for liver stiffness measurement in overweight and obese patients. Hepatology 2012; 55: 199-208.

50. de Lédinghen V, Wong VW, Vergniol J, et al. Diagnosis of liver fibrosis and cirrhosis using liver stiffness measurement: Comparison between $\mathrm{M}$ and XL probe of FibroScan ${ }^{\circledR}$. J Hepatol 2012; 56: 833-839.

51. Lupșor M, Badea R, Ștefănescu H, et al. Performance of unidimensional transient elastography in staging non-alcoholic steatohepatitis. J Gastrointestin Liver Dis 2010; 19: 53-60.

52. Wong VW, Vergniol J, Wong GL, et al. Diagnosis of fibrosis and cirrhosis using liver stiffness measurement in nonalcoholic fatty liver disease. Hepatology 2010; 51: 454-462.

53. Castera L, Vergniol J, Foucher J, et al. Prospective comparison of transient elastography, FibroTest, APRI, and liver biopsy for the assessment of fibrosis in chronic hepatitis C. Gastroenterology 2005; 128: 343-350.

54. Marcellin P, Ziol M, Bedossa P, et al. Non-invasive assessment of liver fibrosis by stiffness measurement in patients with chronic hepatitis B. Liver Int 2009; 29: 242-247.
55. Mueller S, Millonig G, Sarovska L, et al. Increased liver stiffness in alcoholic liver disease: differentiating fibrosis from steatohepatitis. World J Gastroenterol 2010; 16: 966972.

56. Corpechot C, El Naggar A, Poujol-Robert A, et al. Assessment of biliary fibrosis by transient eleastography in patients with PBC and PSC. Hepatology 2006; 43: 11181124.

57. Sasso M, Tengher-Barna I, Ziol M, et al. Novel controlled attenuation parameter for noninvasive assessment of steatosis using Fibroscan( $\left({ }^{\circledR}\right)$ : validation in chronic hepatitis C. J Viral Hepat 2012; 19: 244-253.

58. Lupșor M, Badea R, Ștefănescu H, et al. The performance of controlled attenuation parameter (CAP) for the non-invasive evaluation of steatosis using Fibroscan. Preliminary results. J Hepatol 2012: 56: S514.

59. Sporea I, Raţiu I, Şirli R, Popescu A, Bota S. Value of transient elastography for the prediction of variceal bleeding. World J Gastroentero. 2011; 17: 2206-2210.

60. Nguyen-Khac E, Saint-Leger P, Tramier B, Coevoet H, Capron D, Dupas JL. Noninvasive diagnosis of large esophageal varices by Fibroscan: strong influence of the cirrhosis etiology. Alcohol Clin Exp Res 2010; 34: 11461153.

61. Sporea I, Raţiu I, Bota S, Şirli R, Jurchiş A. Are different cut-off values of liver stiffness assessed by transient elastography according to the etiology of liver cirrhosis for predicting significant esophageal varices? Med Ultrason 2013; 15: 111-115.

62. Shi KQ, Fan YC, Pan ZZ, et al. Transient elastography: a meta-analysis of diagnostic accuracy in evaluation of portal hypertension in chronic liver disease. Liver Int 2013; 33: 62-71.

63. Ștefănescu H, Grigorescu M, Lupşor M, Procopet B, Maniu A, Badea R. Spleen stiffness measurement using Fibroscan for the noninvasive assessment of esophageal varices in liver cirrhosis patients. J Gastroenterol Hepatol 2011; 26: 164-170.

64. Foucher J, Chanteloup E, Vergniol J, et al. Diagnosis of cirrhosis by transient elastography (FibroScan): a prospective study. Gut 2006; 55: 403-408.

65. Masuzaki R, Tateishi R, Yoshida H, et al. Prospective risk assessment for hepatocellular carcinoma development in patients with chronic hepatitis $\mathrm{C}$ by transient elastography. Hepatology 2009; 49: 1954-1961.

66. Feier D, Lupșor Platon M, Ștefănescu H, Badea R. Transient elastography for the detection of hepatocellular carcinoma in viral $\mathrm{C}$ liver cirrhosis. Is there something else than increased liver stiffness? J Gastrointestin Liver Dis 2013; 22: 283-289.

67. Bota S, Sporea I, Șirli R, Dănilă M, Sendroiu M. Factors that influence the correlation of acoustic radiation force impulse (ARFI), elastography with liver fibrosis. Med Ultrason 2011; 13: 135-140.

68. Bota S, Sporea I, Şirli R, Popescu A, Jurchis A. Factors which influence the accuracy of acoustic radiation force impulse (ARFI) elastography for the diagnosis of liver fibrosis 
in patients with chronic hepatitis C. Ultrasound Med Biol 2013; 39: 407-412.

69. Sporea I, Șirli R, Deleanu A, et al. Acoustic radiation force impulse elastography as compared to transient elastography and liver biopsy in patients with chronic hepatopathies. U1traschall Med 2011; 32 Suppl 1: S46-S52.

70. Piscaglia F, Salvatore V, Di Donato R, et al. Accuracy of VirtualTouch Acoustic Radiation Force Impulse (ARFI) imaging for the diagnosis of cirrhosis during liver ultrasonography. Ultraschall Med 2011; 32: 167-175.

71. Toshima T, Shirabe K, Takeishi K, et al. New method for assessing liver fibrosis based on acoustic radiation force impulse: a special reference to the difference between right and left liver. J Gastroenterol 2011; 46: 705-711.

72. Lupşor M, Badea R, Ștefănescu H, et al. Performance of a new elastographic method (ARFI technology) compared to unidimensional transient elastography in the noninvasive assessment of chronic hepatitis C. Preliminary results. J Gastrointestin Liver Dis 2009; 18: 303-310.

73. Fierbințeanu-Braticevici C, Andronescu D, Usvat R, Cretoiu D, Baicus C, Marinoschi G. Acoustic radiation force imaging sonoelastography for noninvasive staging of liver fibrosis. World J Gastroenterol 2009; 15: 5525-5532.

74. Sporea I, Badea R, Șirli R, et al. A. How efficient is acoustic radiation force impulse elastography for the evaluation of liver stiffness? Hepat Mon 2011; 11: 532-538.

75. Fierbințeanu Braticevici C, Sporea I, Panaitescu E, et al. Value of acoustic radiation force impulse imaging elastography for non-invasive evaluation of patients with nonalcoholic fatty liver disease. Ultrasound Med Biol 2013; 39: 1942-1950.

76. Bota S, Sporea I, Sirli R, et al. Factors associated with the impossibility to obtain reliable liver stiffness measurements by means of Acoustic Radiation Force Impulse (ARFI) elastography--analysis of a cohort of 1,031 subjects. Eur J Radiol 2014; 83: 268-272.

77. Bota S, Sporea I, Șirli R, Popescu A, Danila M, Costachescu D. Intra- and interoperator reproducibility of acoustic radiation force impulse (ARFI) elastography--preliminary results. Ultrasound Med Biol 2012; 38: 1103-1108.

78. Boursier J, Isselin G, Fouchard-Hubert I, et al. Acoustic radiation force impulse: a new ultrasonographic technology for the widespread noninvasive diagnosis of liver fibrosis. Eur J Gastroenterol Hepatol 2010; 22: 1074-1084.

79.Li WJ, Wei ZT, Yan RL, Zhang YL. Detection of placenta elasticity modulus by quantitative real-time shear wave imaging. Clin Exp Obstet Gynecol 2012; 39: 470-473.

80. Sugitani M, Fujita Y, Yumoto Y, et al. A new method for measurement of placental elasticity: acoustic radiation force impulse imaging. Placenta 2013; 34: 1009-1013.

81. Popescu A, Bota S, Sporea I, et al. The influence of food intake on liver stiffness values assessed by acoustic radiation force impulse elastography-preliminary results. Ultrasound Med Biol 2013; 39: 579-584.

82. Goertz RS, Egger C, Neurath MF, Strobel D. Impact of food intake, ultrasound transducer, breathing maneuvers and body position on acoustic radiation force impulse
(ARFI) elastometry of the liver. Ultraschall Med 2012; 33: 380-385.

83. Bota S, Sporea I, Peck-Radosavljevic M, et al. The influence of aminotransferase levels on liver stiffness assessed by Acoustic Radiation Force Impulse Elastography: a retrospective multicentre study. Dig Liver Dis 2013; 45: 762768.

84. Yoon KT, Lim SM, Park JY, et al. Liver stiffness measurement using acoustic radiation force impulse (ARFI) elastography and effect of necroinflammation. Dig Dis Sci 2012; 57: 1682-1691.

85. Popescu A, Sporea I, Şirli R, et al. The mean values of liver stiffness assessed by Acoustic Radiation Force Impulse elastography in normal subjects. Med Ultrason 2011; 13: 33-37.

86. Kim JE, Lee JY, Kim YJ, et al. Acoustic radiation force impulse elastography for chronic liver disease: comparison with ultrasound-based scores of experienced radiologists, Child-Pugh scores and liver function tests. Ultrasound Med Biol 2010; 36: 1637-1643.

87. Son CY, Kim SU, Han WK, et al. Normal liver elasticity values using acoustic radiation force impulse imaging: a prospective study in healthy living liver and kidney donors. J Gastroenterol Hepatol 2012; 27: 130-136.

88. Goertz RS, Amann K, Heide R, Bernatik T, Neurath MF, Strobel D. An abdominal and thyroid status with Acoustic Radiation Force Impulse Elastometry - a feasibility study: Acoustic Radiation Force Impulse Elastometry of human organs. Eur J Radiol 2011; 80: e226-e230.

89. Karlas T, Pfrepper C, Wiegand J, et al. Acoustic radiation force impulse imaging (ARFI) for non-invasive detection of liver fibrosis: examination standards and evaluation of interlobe differences in healthy subjects and chronic liver disease. Scand J Gastroenterol 2011; 46: 1458-1467.

90. Madhok R, Tapasvi C, Prasad U, Gupta AK, Aggarwal A. Acoustic radiation force impulse imaging of the liver: measurement of the normal mean values of the shearing wave velocity in a healthy liver. J Clin Diagn Res 2013; 7: $39-42$.

91. Sporea I, Şirli R, Bota S, et al. Is ARFI elastography reliable for predicting fibrosis severity in chronic HCV hepatitis? World J Radiol 2011; 3: 188-193.

92. Sporea I, Şirli R, Bota S, Popescu A, Sendroiu M, Jurchis A. Comparative study concerning the value of acoustic radiation force impulse elastography (ARFI) in comparison with transient elastography (TE) for the assessment of liver fibrosis in patients with chronic hepatitis B and C. Ultrasound Med Biol 2012; 38: 1310-1316.

93. Nierhoff J, Chávez Ortiz AA, Herrmann E, Zeuzem S, Friedrich-Rust M. The efficiency of acoustic radiation force impulse imaging for the staging of liver fibrosis: a metaanalysis. Eur Radiol 2013; 23: 3040-3053.

94. Bota S, Herkner H, Sporea I, et al. Meta-analysis: ARFI elastography versus transient elastography for the evaluation of liver fibrosis. Liver Int 2013; 33: 1138-1147.

95. Bota S, Sporea I, Şirli R, et al. Can ARFI elastography predict the presence of significant esophageal varices in 
newly diagnosed cirrhotic patients? Ann Hepatol 2012; 11: 519-525.

96. Vermehren J, Polta A, Zimmermann O, et al. Comparison of acoustic radiation force impulse imaging with transient elastography for the detection of complications in patients with cirrhosis. Liver Int 2012; 32: 852-858.

97. Takuma Y, Nouso K, Morimoto Y, et al. Measurement of spleen stiffness by acoustic radiation force impulse imaging identifies cirrhotic patients with esophageal varices. Gastroenterology 2013; 144: 92-101.e2.

98. Morishita N, Hiramatsu N, Oze T, et al. Liver stiffness measurement by acoustic radiation force impulse is useful in predicting the presence of esophageal varices or highrisk esophageal varices among patients with HCV-related cirrhosis. J Gastroenterol 2013 Sep 5.

99. Bota S, Sporea I, Șirli R, Popescu A, Dănilă M, Sendroiu $\mathrm{M}$. The influence of liver residual mass on the values of Acoustic Radiation Force Impulse Elastography (ARFI) in cirrhotic patients. Med Ultrason 2011; 13: 195-199.

100. Şirli R, Sporea I, Bota S, et al. Can Acoustic Radiation Force Impulse Elastography (ARFI) predict the complications of liver cirrhosis? Medicina Interna 2010;7:15-20.

101. Ling W, Lu Q, Quan J, Ma L, Luo Y. Assessment of impact factors on shear wave based liver stiffness measurement. Eur J Radiol 2013; 82: 335-341.

102. Ma JJ, Ding H, Mao F, Sun HC, Xu C, Wang WP. Assessment of liver fibrosis with elastography point quantification technique in chronic hepatitis B virus patients: A comparison with liver pathological results. J Gastroenterol Hepatol 2014; 29: 814-819.

103. Sporea I, Bota $\mathrm{S}$, Grădinaru-Taşcău $\mathrm{O}$, et al. Comparative study between two point Shear Wave elastographic techniques: Acoustic Radiation Force Impulse (ARFI) elastography and ElastPQ technique. EPOS ECR 2014, DOI:10.1594/ECR2014/C-1127. http://dx.doi. org/10.1594/ecr2014/C-1127.

104. Ferraioli G, Tinelli C, Lissandrin R, et al. Performance of ElastPQ ${ }^{\circledR}$ Shear Wave Elastography Technique for Assessing Fibrosis in Chronic Viral Hepatitis. J Hepatol 2013; 58 (Suppl 1): S7.

105. Leung VY, Shen J, Wong VW, et al. Quantitative elastography of liver fibrosis and spleen stiffness in chronic hepatitis B carriers: comparison of shear-wave elastography and transient elastography with liver biopsy correlation. Radiology 2013; 269: 910-918.

106. Ferraioli G, Tinelli C, Dal Bello B, et al; Liver Fibrosis Study Group. Accuracy of real-time shear wave elastography for assessing liver fibrosis in chronic hepatitis $\mathrm{C}$ : a pilot study. Hepatology 2012; 56: 2125-2133.

107. Bavu E, Gennisson JL, Couade M, et al. Noninvasive in vivo liver fibrosis evaluation using supersonic shear imaging: a clinical study on 113 hepatitis $\mathrm{C}$ virus patients. Ultrasound Med Biol 2011; 37: 1361-1373.

108. Yoon JH, Lee JM, Woo HS, et al. Staging of hepatic fibrosis: comparison of magnetic resonance elastography and shear wave elastography in the same individuals. Korean J Radiol 2013; 14: 202-212.
109. Sporea I, Bota S, Jurchiș A, et al. Acoustic radiation force impulse and supersonic shear imaging versus transient elastography for liver fibrosis assessment. Ultrasound Med Biol 2013; 39: 1933-1941.

110. Sporea I, Grădinaru-Taşcău O, Bota S, et al. How many measurements are needed for liver stiffness assessment by 2D-Shear Wave Elastography (2D-SWE) and which value should be used: the mean or median? Med Ultrason 2013; 15: 268-272.

111. Hudson JM, Milot L, Parry C, Williams R, Burns PN. Inter- and intra-operator reliability and repeatability of shear wave elastography in the liver: a study in healthy volunteers. Ultrasound Med Biol 2013; 39: 950-955.

112. Poynard T, Munteanu M, Luckina E, et al. Liver fibrosis evaluation using real-time shear wave elastography: applicability and diagnostic performance using methods without a gold standard. J Hepatol 2013; 58: 928935.

113. Ferraioli G, Tinelli C, Zicchetti M, et al. Reproducibility of real-time shear wave elastography in the evaluation of liver elasticity. Eur J Radiol 2012; 81: 3102-3106.

114. Grădinaru-Taşcău $\mathrm{O}$, Sporea I, Bota S, et al. Does experience play a role in the ability to perform liver stiffness measurements by means of supersonic shear imaging (SSI)? Med Ultrason 2013; 15: 180-183.

115. Vonghia L, Werlinden W, Pelckmans P, Michielsen P, Francque S. Liver stiffness by shear wave elastography is influenced by meal and meal-related haemodynamic modifications. Ultraschall Med 2013; 34 - WS_SL24_09. DOI: $10.1055 / \mathrm{s}-0033-1354961$.

116. Șirli R, Bota S, Sporea I, et al. Liver stiffness measurements by means of supersonic shear imaging in patients without known liver pathology. Ultrasound Med Biol 2013; 39: 1362-1367.

117. Sporea I, Bota S, Grădinaru-Taşcău O, Sirli R, Popescu A, Jurchiş A. Which are the cut-off values of 2D-Shear Wave Elastography (2D-SWE) liver stiffness measurements predicting different stages of liver fibrosis, considering Transient Elastography (TE) as the reference method? Eur J Radiol 2014; 83: e118-e122.

118. Săndulescu L, Rogoveanu I, Gheonea IA, Cazacu S, Săftoiu A. Real-time elastography applications in liver pathology between expectations and results. J Gastrointestin Liver Dis 2013; 22: 221-227.

119. Kudo M, Shiina T, Moriyasu F, et al. JSUM ultrasound elastography practice guidelines: liver. J Med Ultrasonics 2013; 40: 325-357.

120. Gheonea DI, Săftoiu A, Ciurea T, et al. Real-time sonoelastography in the diagnosis of diffuse liver diseases. World J Gastroenterol 2010; 16: 1720-1726.

121. Koizumi Y, Hirooka M, Kisaka Y, et al. Liver fibrosis in patients with chronic hepatitis $\mathrm{C}$ : noninvasive diagnosis by means of real-time tissue elastography--establishment of the method for measurement. Radiology 2011; 258: 610-617.

122. Săftoiu A, Gheonea DI, Ciurea T. Hue histogram analysis of real-time elastography images for noninvasive assess- 
ment of liver fibrosis. AJR Am J Roentgenol 2007; 189: W232-W233.

123. Hirooka M, Koizumi Y, Hiasa Y, et al. Hepatic elasticity in patients with ascites: evaluation with real-time tissue elastography. AJR Am J Roentgenol 2011; 196: W766-W771.

124. Carlsen JF, Ewertsen C, Săftoiu A, Lönn L, Nielsen MB. Accuracy of visual scoring and semi-quantification of ultrasound strain elastography - a phantom study. PLoS One 2014; 9:e88699.

125. Kanamoto M, Shimada M, Ikegami T, et al. Real time elastography for noninvasive diagnosis of liver fibrosis. J Hepatobiliary Pancreat Surg 2009; 16: 463-467.

126. Săndulescu L, Săftoiu A, Rogoveanu I, et al. Real-time sono-elastography for non invasive assessment of diffuse liver disease. 22nd Congress of EFSUMB, Copenhagen, 22-25.08.2010, Final Programme and abstracts, PE 40, 117.

127. Morikawa H, Fukuda K, Kobayashi S, et al. Real-time tissue elastography as a tool for the noninvasive assessment of liver stiffness in patients with chronic hepatitis C. J Gastroenterol 2011; 46: 350-358.

128. Yada N, Kudo M, Morikawa H, Fujimoto K, Kato M, Kawada N. Assesment of liver fibrosis with real time elastography in chronic viral hepatitis. Oncology 2013; 84 Suppl 1: 13-20.
129. Wang J, Guo L, Shi X, Pan W, Bai Y, Ai H. Real-time Elastography with a novel quantitative technology for assessment of liver fibrosis in chronic hepatitis B. Eur J Radiol 2012; 81: e31-e36.

130. Gheorghe L, Iacob S, Iacob R, et al. Real time elastography - a non-invasive diagnostic method of small hepatocellular carcinoma in cirrhosis. J Gastrointestin Liver Dis 2009; 18: 439-446.

131. Goertz RS, Amann K, Heide R, Bernatik T, Neurath MF, Strobel D. An abdominal and thyroid status with Acoustic Radiation Force Impulse Elastometry-a feasibility study: Acoustic Radiation Force Impulse Elastometry of human organs. Eur J Radiol 2011; 80: e226-e230.

132. Shuang-Ming T, Ping Z, Ying Q, Li-Rong C, Ping Z, RuiZhen L. Usefulness of acoustic radiation force impulse imaging in the differential diagnosis of benign and malignant liver lesions. Acad Radiol 2011; 18: 810-815.

133. Havre RF, Waage JR, Gilja OH, Odegaard S, Nesje LB. Real-Time Elastography: Strain Ratio Measurements Are Influenced by the Position of the Reference Area. Ultraschall Med 2011 Jun 10.

134. Ying L, Lin X, Xie ZL, Tang FY, Hu YP, Shi KQ. Clinical utility of acoustic radiation force impulse imaging for identification of malignant liver lesions: a meta-analysis. Eur Radiol 2012; 22: 2798-2805. 